\title{
Cardiac involvement of myotonic dystrophy type II in patients with preserved ejection fraction - Detection by CMR
}

\author{
Luisa M Schmacht ${ }^{1 *}$, Julius Traber ${ }^{1}$, Ulrike I Grieben², Wolfgang Utz ${ }^{1}$, Matthias A Dieringer ${ }^{1}$, Peter Kellman ${ }^{3}$, \\ Simone Spuler ${ }^{2}$, Jeanette Schulz-Menger ${ }^{1}$
}

From 18th Annual SCMR Scientific Sessions

Nice, France. 4-7 February 2015

\section{Background}

Myotonic dystrophy type II (MD2) is a genetic multisystemic disorder characterized by skeletal muscle (SM) symptoms, metabolic changes as well as arrhythmias ${ }^{1}$. Histopathologic changes of the SM may include fibrosis and fatty degeneration ${ }^{2}$. The aim of this study is to evaluate myocardial structure in preserved ejection fraction (EF).

\section{Methods}

We prospectively enrolled 32 subjects with a genetically confirmed diagnosis of MD2. Exclusion criteria were known cardiac diseases and contraindication for CMR. We assessed left-ventricular (LV) volumes, mass and function applying state of the art cine imaging using a $1.5 \mathrm{~T}$ Scanner. Late enhancement imaging (LGE; slice thickness (sth) $7 \mathrm{~mm}$ ) was performed to detect myocardial fibrosis 10 minutes after injection of gadoteridol $(0.2 \mathrm{mmol} / \mathrm{kgbw})$. We applied T1 Mapping based on MOLLI (TI native 211 $\mathrm{ms}$, TI post-contrast $281 \mathrm{~ms}$, TE $1.08 \mathrm{~ms}$, sth $6 \mathrm{~mm}$ ) before and 15 minutes after contrast application and assessed resultant extracellular volume fraction (ECV). Fat-water-separated imaging ${ }^{3}$ (GRE, TR $944.80 \mathrm{~ms}$, TE 1.53-8.22 ms, sth $6 \mathrm{~mm}$ ) was performed to identify myocardial fat deposits. Furthermore, we used ${ }^{1} \mathrm{H}$ magnetic resonance spectroscopy (MRS) (TR $1600 \mathrm{~ms}$, TE $35 \mathrm{~ms}$, septal voxel $20 \times 15 \times 6 \mathrm{~mm}^{3}$ ) to quantify myocardial Triglycerides (MTG). Data were analyzed using $\mathrm{cvi}^{42}$ and standard line-fitting procedure.

${ }^{1}$ Cardiology, ECRC, Charité University Medicine Berlin and HELIOS Clinics, Berlin, Germany

Full list of author information is available at the end of the article

\section{Results}

26 data sets were totally completed (age $53.8 \pm 11$ y, LVEF $65 \pm 0.6 \%, 19$ women). None of the patients had wall motion abnormalities. LGE was detectable in 6 of 28 subjects (LGE+; 3 women); the location was mostly subepicardial inferolateral basal (Figure 1). In case of LGE+, the T1-values of the enhanced regions were significantly different to remote myocardium in both the native $(\mathrm{p}=0.03)$ and the post-contrast maps $(\mathrm{p}=0.03)$. $\mathrm{ECV}$ and $\mathrm{T} 1$ values of the remote myocardium were not different between LGE + and LGE negative (LGE-) groups besides to the inferolateral located ECV (25.6\% vs. $34.3 \%, p=0.03$ ) (Figure 2). Fat deposits were noticeable in 6 of 30 subjects (all women, one with LGE + ) in the apical portion of the interventricular septum. The content of MTG in LGE+ and LGE- subjects was not significant different $(0.34 \%$ vs. $0.74 \%, \mathrm{p}=0.47)$.

\section{Conclusions}

Despite preserved LVEF we could detect myocardial injury in patients with myotonic dystrophy type II. Already native $\mathrm{T} 1$-values were increased in case of subepicardial fibrosis compared to remote myocardium. To conclude, this is the first study constituted that CMR is feasible to detect subclinical myocardial manifestations in MD2.

\section{Funding}

N/A.

Authors' details

${ }^{1}$ Cardiology, ECRC, Charité University Medicine Berlin and HELIOS Clinics, Berlin, Germany. ${ }^{2}$ Neurology, ECRC, Charité University Medicine Berlin, Berlin, Germany. ${ }^{3}$ Laboratory of Cardiac Energetics, National Institutes of Health, Bethesda, MD, USA. 


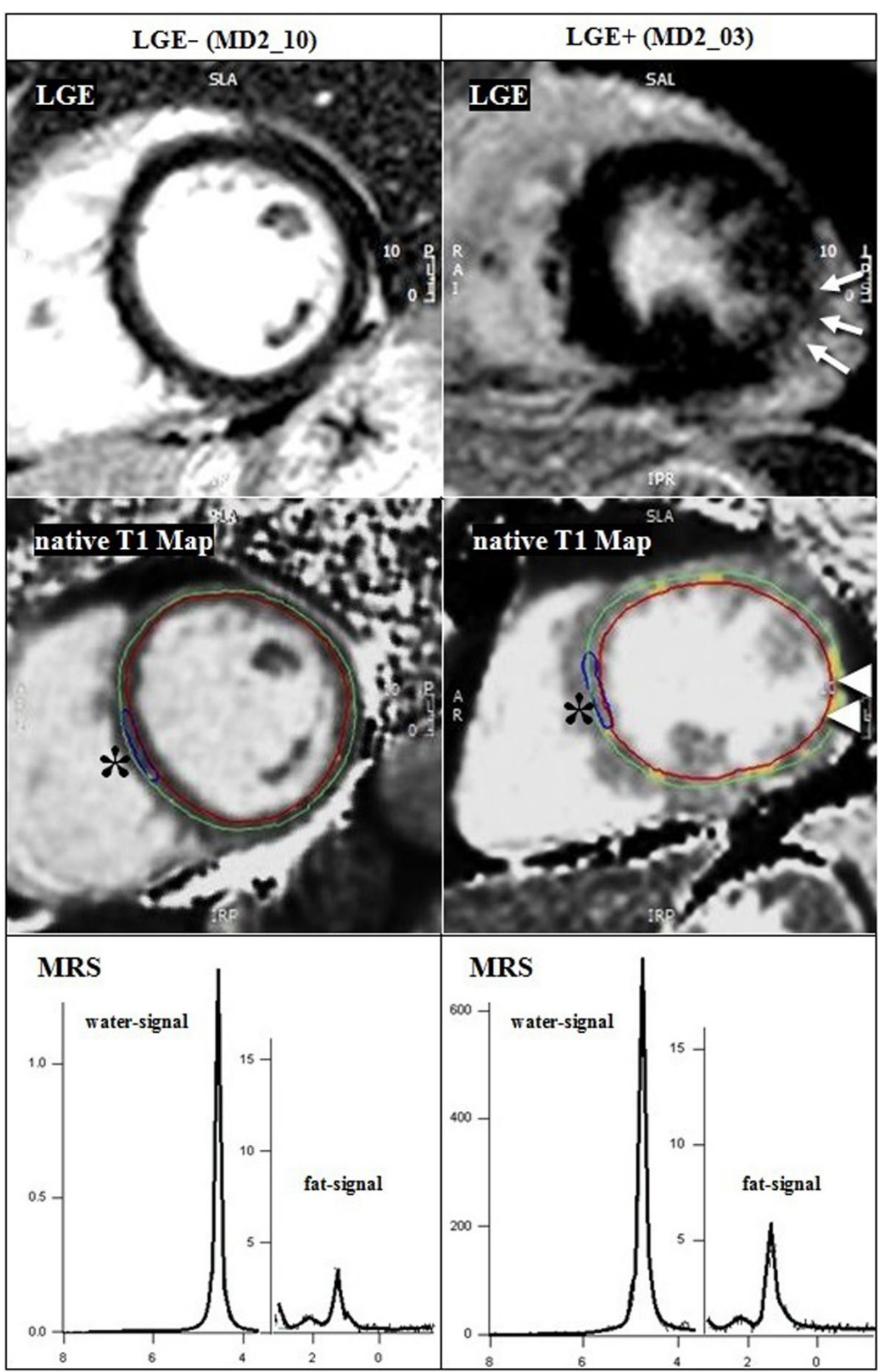

Figure 1 Image findings in LGE negative (LGE-, on the left) and positive (LGE+, on the right) patients. On top the LGE images, followed by native T1 Maps and MRS spectra. Arrows: LGE+; colored voxels (arrowheads): T1 values + 2 standard deviations to the reference myocardium (stars) 


\begin{tabular}{|c|c|c|c|c|c|}
\hline & & LGE- $(n=22)$ & $\mathbf{L G E}+(\mathrm{n}=6)$ & $\begin{array}{c}\text { p-value } \\
\text { (Mann- } \\
\text { Whitney) }\end{array}$ & $\begin{array}{c}\text { correlation } \\
\text { to LGE+ } \\
\text { (Spearman) }\end{array}$ \\
\hline & $\operatorname{sex}$ & 18 women $(82 \%)$ & 3 women $(50 \%)$ & 0.12 & -0.30 \\
\hline & age (years) & $52.3 \pm 10$ & $62,8 \pm 11$ & 0.15 & 0.28 \\
\hline \multicolumn{2}{|c|}{ Body-Mass-Index $\left(\mathrm{kg} / \mathrm{m}^{2}\right)$} & $23.6 \pm 3$ & $25,5 \pm 2$ & 0.28 & 0.21 \\
\hline \multicolumn{2}{|c|}{ LV Ejection Fraction (\%) } & $0.66 \pm 0.07$ & $0,62 \pm 0,05$ & 0.14 & -0.28 \\
\hline \multicolumn{2}{|c|}{ LV-EDV-Index (ml/cm) } & $0.8 \pm 0.1$ & $0,8 \pm 0,1$ & 0.23 & 0.23 \\
\hline \multicolumn{2}{|c|}{ LV-Mass-Index (g/cm) } & $0.6 \pm 0.1$ & $0.7 \pm 0.2$ & 0.10 & 0.33 \\
\hline \multicolumn{2}{|r|}{ MTG (\%) } & $\begin{array}{c}0.34 \pm 0.20 \\
(0.03-0.78)\end{array}$ & $\begin{array}{c}0.74 \pm 0.96 \\
(0.01-2.36)\end{array}$ & 0.47 & 0.15 \\
\hline \multicolumn{2}{|c|}{$\begin{array}{r}\text { apical fat in fat/water } \\
\text { separated imaging }\end{array}$} & 5 (all women) & 1 (woman) & 0.72 & -0.07 \\
\hline \multirow{2}{*}{$\begin{array}{l}\text { T1 value (ms) } \\
\text { native Maps }\end{array}$} & septal & $\begin{array}{c}1024 \pm 28 \\
(980-1085)\end{array}$ & $\begin{array}{c}1042 \pm 49 \\
(994-1119)\end{array}$ & 0.82 & 0.04 \\
\hline & inferolateral & $\begin{array}{c}1027 \pm 41 \\
(965-1111)\end{array}$ & $\begin{array}{c}1087 \pm 93 \\
(1012-1249) \\
\end{array}$ & 0.05 & 0.37 \\
\hline \multirow{2}{*}{$\begin{array}{c}\text { T1 values (ms) } \\
\text { post-contrast } \\
\text { Maps }\end{array}$} & septal & $\begin{array}{c}469 \pm 38 \\
(385-535)\end{array}$ & $\begin{array}{c}471 \pm 33 \\
(430-517)\end{array}$ & 0.86 & 0.03 \\
\hline & inferolateral & $\begin{array}{c}463 \pm 35 \\
(396-511)\end{array}$ & $\begin{array}{c}426 \pm 44 \\
(371-488)\end{array}$ & 0.06 & -0.37 \\
\hline \multirow{2}{*}{$\operatorname{ECV}(\%)$} & septal & $24.8 \pm 3$ & $27.7 \pm 4$ & 0.15 & 0.30 \\
\hline & inferolateral & $25.6 \pm 3$ & $34.3 \pm 8$ & 0.003 & $0.62^{*}$ \\
\hline
\end{tabular}

Figure 2 Comparison of LGE negative (LGE-) and LGE positive (LGE+) subjects. The inferolateral extracellular volume fraction (ECV) was significantly different in these two groups. MTG: Content of myocardial triglycerides measured by magnetic resonance spectroscopy. ${ }^{*}$ The correlation to LGE+ was significant $(p<0.01)$

Published: 3 February 2015

\section{References}

1. Day JW, et al: Myotonic dystrophy type 2 molecular, diagnostic and clinical spectrum. Neurology 2003, 60:657-664.

2. Schoser $B$, et al: Muscle pathology in 57 patients with myotonic dystrophy type 2. Muscle Nerve 2004, 29:275-281.

3. Kellman P, et al: Multiecho dixon fat and water separation method for detecting fibrofatty infiltration in the myocardium. Magn Reson Med 2009, 61(1):215-21.

- Convenient online submission

- Thorough peer review

- No space constraints or color figure charges

- Immediate publication on acceptance

- Inclusion in PubMed, CAS, Scopus and Google Scholar

- Research which is freely available for redistribution 